\title{
Knowledge, attitude and practices of ASHAs regarding tuberculosis and DOTS
}

\author{
S. M. Sagare ${ }^{1^{*}}$, R. R. Bogam ${ }^{2}$, S. K. Murarkar ${ }^{3}$, U. P. Patil ${ }^{4}$ and M. M. Ghate ${ }^{5}$ \\ Department of Community Medicine, Bharati Vidyapeeth Deemed University Medical College, Pune-411043. \\ Maharashtra State, India \\ drsmsagare@gmail.com*,rhl_bogam@yahoo.co.in, sujata.murarkar@gmail.com, ushapatil747584@yahoo.com, \\ mrghate@rediffmail.com
}

\begin{abstract}
One of the key components of the National Rural Health Mission (NRHM) is to provide every village, Accredited Social Health Activist (ASHA). Directly Observed Treatment Short course (DOTS) provider, if accessible and acceptable to patient and accountable to health system, can play a significant role in reducing TB burden. ASHA can be a DOTS provider under Revised National Tuberculosis Control Programme. The present study attempts to understand KAP (Knowledge, Attitude and Practice) of ASHAs pertaining to tuberculosis and DOTS. Modified Sample ACSM KAP Survey questionnaire on tuberculosis was used to collect information. Total $43(91.48 \%)$ out of 47 ASHAs participated in the study. Mean age of them was 29.55 years. Good knowledge (Mean score $=6.58$ out of 10) was observed regarding tuberculosis and DOTS. All were well known that tuberculosis can be cured with prompt treatment. Twenty nine $(67.44 \%)$ ASHAs knew correctly that the tuberculosis diagnosis and DOTS is totally free of cost. Forty one $(95.34 \%)$ ASHAs preferred to go to health facility if they thought that they themselves had symptoms of tuberculosis. Thirty eight (88.37\%) ASHAs had a favourable attitude towards tuberculosis patients. Study revealed good knowledge, favourable attitudes and practices pertaining to tuberculosis amongst ASHAs. However, gaps in the knowledge of BCG vaccination and major symptoms of pulmonary tuberculosis were observed.
\end{abstract}

Keywords: NRHM, ASHA, RNTCP, DOTS. Tuberculosis.

\section{Introduction}

The National Rural Health Mission (NRHM) was launched on $12^{\text {th }}$ April 2005. One of the key components of the NRHM is to provide every village in the country with trained female community health activist- Accredited Social Health Activist (ASHA). She mobilises community and facilitate them in accessing health and related services available at the village /sub centre/primary health centres, such as immunization, antenatal check-up (ANC), post natal check-up, supplementary nutrition, sanitation and other services being provided by government

(http://mohfw.nic.in/NRHM/RCH/guidelines/ASHA_guideli nes.pdf). India is the highest TB burden country in the world and accounts for nearly one fifth (20\%) of global burden of tuberculosis (Park, 2009). In India today, two deaths occur every three minutes from tuberculosis but these deaths can be prevented (http://www.tbcindia.org/RNTCP.asp).

Directly Observed Treatment Short course (DOTS) is a strategy for ensuring high cure rates in patients with tuberculosis. DOT provider if accessible and acceptable to patient and accountable to health system, can play a significant role in reducing TB burden of country. ASHA can be a DOTS provider under Revised National Tuberculosis Control Programme (RNTCP) (Guidelines on Accredited Social Health Activists, 2011). The present study attempted to understand KAP of ASHAs pertaining to tuberculosis as envisaged under RNTCP.

\section{Material and methods}

On occasion of World Tuberculosis Day (March 24, 2011), 'Tuberculosis Awareness Programme and Quiz Competition' was organized for all ASHAs working in field practice area of Rural Health Training centre (RHTC), Lavale of Bharati Vidyapeeth Deemed University Medical College, Pune. Rural Health Training Centre of medical college caters to approximately 47000 population spread over in 11 villages. This is a questionnaire based KAP (Knowledge, Attitude and Practice) study. Sample ACSM (Advocacy, communication and social mobilization) KAP Survey questionnaire was modified in local language and was used to assess KAP of ASHAs regarding tuberculosis and DOTS (ACSM, 2011).

\section{Sampling}

In general norm under NRHM, 'One ASHA per 1000 population' is selected to give services in rural areas (Guidelines on Accredited Social Health Activists, 2011). As Rural Health Training Centre caters approximately 47000 population, we have 47 working ASHAs (1 per 1000 population). All were invited to participate in the study. However after obtaining written informed consent, total 43 ASHAs participated in the study. All participants were explained in detail about filling of questionnaire. Total 20 minutes were allowed to complete questionnaire under strict supervision. Subsequently the pre-decided 'Tuberculosis Awareness Programme and Quiz Competition' was conducted by trained facilitators. The questionnaire consisted of 20 close ended questions, of which 11 were knowledge based and remaining 9 questions were related to attitude and practices regarding
Sci.Technol.Edu

(C)Indian Society for Education and Environment (iSee)
"Role of ASHAs in TB management" http://www.indjst.org
Sagare et al. Indian J.Sci.Technol. 
tuberculosis and DOTS. As 1 of 11 knowledge based questions was correctly responded by all 43 ASHAs i.e. tuberculosis is known as 'Kshayroga' in local language, the remaining 10 questions were assigned scoring system. One score was given for correct response and zero for incorrect response.

For one question pertaining to symptomatology of pulmonary tuberculosis, one score was given for responding all three major symptoms of pulmonary TB and zero for responding less than three symptoms.

The mean score equal or below five was classified as having poor knowledge while score more than five out of ten was considered to have good knowledge. For attitude and practice related questions no scoring was given. Only percentages of different responses were considered to see different attitudes and practices amongst ASHAs.

\section{Results}

Undergraduate and postgraduate

Table 1. Socio demographic and other characteristics of ASHAs

\begin{tabular}{|c|c|c|}
\hline Sr. No. & Characteristics of ASHAs & No. (\%) \\
\hline \multirow[t]{4}{*}{1} & Age & \\
\hline & $19-24$ & 09(20.93) \\
\hline & $25-34$ & $29(67.44)$ \\
\hline & $35-45$ & $05(11.63)$ \\
\hline \multirow[t]{4}{*}{2} & Educational class & \\
\hline & $5^{\text {th }}-7^{\text {th }}$ & 09 (20.93) \\
\hline & $8^{\mathrm{th}}-12^{\mathrm{th}}$ & $32(74.42)$ \\
\hline & UG and $P G^{\pi}$ & $02(4.65)$ \\
\hline \multirow[t]{3}{*}{3} & Family Composition & \\
\hline & Nuclear & 17(39.53) \\
\hline & Joint & $26(60.47)$ \\
\hline \multirow[t]{3}{*}{4} & Marital status & \\
\hline & Married & $40(93.02)$ \\
\hline & Widow & $03(6.98)$ \\
\hline \multirow[t]{3}{*}{5} & $\begin{array}{l}\text { Work duration as ASHA (in } \\
\text { years) }\end{array}$ & \\
\hline & $\leq 1$ & $02(4.65)$ \\
\hline & $2-4$ & 41(95.34) \\
\hline \multirow[t]{3}{*}{6} & Other income sources & \\
\hline & Yes & 19 (44.19) \\
\hline & No & $24(55.81)$ \\
\hline \multirow[t]{3}{*}{7} & Support from supervisors & \\
\hline & Yes & $41(95.34)$ \\
\hline & No & $02(4.65)$ \\
\hline
\end{tabular}

Table 1 shows socio demographic and other characteristics of ASHAs. Total 43 (91.48\%) out of 47 ASHAs participated in the study. Mean age of them was found to be 29.55 years with $34(79.07 \%)$ ASHAs in the age group of $25-45$ years and remaining 9 (20.93\%) were from age group of 19-24 years. All ASHAs were literate and completed education up to primary level. More than three fourth of ASHAs i.e. 34(79.07\%) had education from $8^{\text {th }}$ class up to post graduate level. Nineteen $(44.19 \%)$ ASHAs mentioned that they had additional sources of income but only $9(20.93 \%)$ of them specified details of income sources. Sewing was mentioned by 4 followed by farming by 3 ASHAs. Making food in school and service at NGO was mentioned by one ASHA each.

\section{Discussion}

NRHM guidelines states that ASHA must be primarily a woman resident of the village, preferably, in the age group of 25 to 45 years, 'Married/Widow/Divorced' with formal education up to eighth class (Hota \& Dobe, 2005). In the present study, age bracket of ASHAs was found to be from 19-45 years with mean age of 29.55 years. Nine (20.93\%) ASHAs were from 19-24 years age group, which did not fulfil age selection criteria. Probably this age relaxation might have been given during their selection on the basis of education and marital status criteria. Though 9 ASHAs did not fulfil the age criteria as per NRHM guidelines, their knowledge pertaining to tuberculosis and DOTS was also found to be good (Mean Score $=7.5)$. Present study found $26(60.47 \%)$ ASHAs were in age group of 19-30 years, which corroborate with findings of Srivastava et al. (2009) who also identified more than half $(53.33 \%)$ of ASHAs were in the age group of 20-29 years.

Based on myriad experiences of NGO health worker programmes, Abhay shukla, (2005) quoted that insisting on formal education is not necessary; provided the training of health workers is properly designed. However an education criterion in this study has been fulfilled completely with majority of ASHAs (79.07\%) having education above $8^{\text {th }}$ class. In present study, good knowledge was observed amongst ASHAs regarding tuberculosis i.e. Mean score (S.D.) out of $10=$ 6.58(1.40).

As per RNTCP guidelines (Suryakanta, 2010) three major symptoms of pulmonary tuberculosis are cough with or without expectoration for 2 weeks or more, gradual onset of low grade fever with evening rise and weight loss and fatigue. Only 4 ((9.3\%) ASHA could state all three major symptoms of pulmonary tuberculosis. Surprisingly all $43(100 \%)$ ASHAs were found to be aware with recent guidelines of cough with or without expectoration for 2 or more than 2 weeks duration as a most common symptom of pulmonary tuberculosis.

Similarly in baseline KAP study under RNTCP project of opinion leaders (Anganwadi workers, Mahila mandal representatives, ANMs, Religious leaders etc.), it was found that in all the states the most mentioned symptom was a cough of three weeks, followed by fever (http://www.tbcindia.org/pdfs/Baseline\%20KAP\%20Study \%20under\%20RNTCP\%20Project\%20-\%20CMS.pdf).

Same symptoms of tuberculosis were stated by Anganwadi workers and health care workers (Majra, 2008).

The study thus revealed that all ASHAs were well versed with recent guidelines of RNTCP about pulmonary TB suspects i.e. cough with or without expectoration for 2 or more than 2 weeks rather than 3 weeks. Nearly two third of ASHAs i.e. 28 (65.11\%) could correctly state that
Sci.Technol.Edu

Clndian Society for Education and Environment (iSee)
Sagare et al. Indian J.Sci.Technol. 
the pulmonary tuberculosis spreads from one person to another person through air. Of remaining 15 ASHAs, 5 did not give any response, 6 selected blood, 3 elected mosquitoes and one opted water as possible mode of tuberculosis transmission. Nearly all ASHAs i.e. $39(90.69 \%)$ were aware that TB can infect any person irrespective of socioeconomic status or HIV status. One felt that only alcoholic person can be infected with tuberculosis. No response was given by 3 (6.98\%) ASHAs. However no one had chosen that only poor or homeless people can be infected with TB.

Present study revealed good knowledge regarding diagnosis of tuberculosis patients. Thirty-eight (88.37\%) ASHAs stated that sputum examination is reliable method of diagnosis of pulmonary tuberculosis patient. Four $(9.30 \%)$ thought $x$-ray and one $(2.33 \%)$ said that all i.e. blood, sputum, urine and $\mathrm{x}$ - ray are reliable tests for diagnosis of pulmonary TB.

In contrast to present study findings, poor knowledge was observed among opinion leaders (Baseline KAP Study under RNTCP Project, 2011), where $60 \%$ of them in various states recognized $\mathrm{x}$-ray as a reliable method for diagnosing tuberculosis.

DOTS identified as the 'key' strategy to control tuberculosis under RNTCP. Forty-one (95.34\%) ASHAs precisely mentioned DOTS is the most effective strategy for tuberculosis cure and two did not chosen any option. However none of ASHAs mentioned ayurvedic/herbal medicines, home rest or praying as an effective strategy for tuberculosis cure, indicating the concept of DOTS in curing tuberculosis was clearly understood to all ASHAs. The average duration of DOTS regimen i.e. 6-8 months, was correctly stated by 24(55.81\%) ASHAs and 26 $(60.47 \%)$ stated correctly that the drugs are given thrice a week under DOTS regimen.

Majority of the opinion leaders rightly identified the duration of treatment of DOTS as six months in a baseline KAP survey while $93.6 \%$ and $4.4 \%$ of health care workers in Iraq (Hashim et al., 2003) specified 6-9 months and 2-3 months respectively. Only 19 (23.2\%) nurses in tuberculosis institute and $24(18.3 \%)$ nurses in general hospital mentioned as 6 months is the minimum duration of short-course chemotherapy (Neeta Singla et al., 1998).

Tuberculosis diagnosis and DOTS is totally free of charge under RNTCP Programme (Reading material for ASHA. Book No-4, July 2006). Only two third of ASHAs i.e. $29(67.44 \%)$ knew correctly that the tuberculosis diagnosis and DOTS is totally free of cost. Present study revealed gaps in knowledge about BCG vaccine. It was surprising to know that only $13(30.23 \%)$ ASHAS were well versed with fact that there is a vaccine for tuberculosis and of them, only $3(6.98 \%)$ could name it correctly i.e. BCG.

All 43 (100 \%) ASHA agreed that with prompt treatment tuberculosis can be cured. Similar findings were observed in a baseline report of CMS (Baseline KAP Study under RNTCP Project, 2011).

More than half of ASHAs i.e. $25(58.14 \%)$ considered TB is a serious disease. Fourteen (32.56\%) and $11(25.58 \%)$ ASHAs felt that TB is very serious and somewhat serious respectively. Fourteen (32.56\%) felt that TB is not serious and $4(9.3 \%)$ could not recognize the seriousness of disease.

In present study, comparatively better attitude towards seriousness of tuberculosis has been observed amongst ASHAs than general population of Iraq (Thamer Kadum et al., 2009). This could be attributed to education level and sustained training of ASHAs pertaining to tuberculosis. All ASHAs (100\%) were well known that tuberculosis can be prevented by covering mouth and nose while coughing or sneezing.

Nearly all ASHAs i.e. 38 (90.69\%) had a favourable attitude towards tuberculosis patients stating that they feel compassion and desire to help tuberculosis patients except one. She would like to stay away from these people. Two (4.65\%) ASHAs had fear of getting TB from infected persons. Three (6.98\%) did not show any reaction towards people infected with tuberculosis. Mengiste et al., (2005) mentioned $76.3 \%$ of community health workers had fear to contact a TB patient.

Tuberculosis patients are treated in different ways according to ASHAs. Nearly half of ASHAs i.e. $20(46.51 \%)$, stated that the community mostly supports and helps them. Fifteen (34.88\%) ASHAs said that most people in the community are friendly but they generally try to avoid them. Three $(6.98 \%)$ ASHAs felt that such people are rejected by community, however $5(11.63 \%)$ ASHAs had given no any response. In contrast, Muhammad Umair Mushtaq et al. (2011) reported nearly half of the respondents believed that the community rejects TB patients in two districts of Pakistan-Punjab province. It clearly indicates that the rejection of tuberculosis patients by community in India is less $(6.98 \%)$ than Pakistan.

Forty-one (95.34\%) ASHAs preferred to go health facility if they thought that; they themselves had symptoms of tuberculosis. However remaining two $(4.65 \%)$ preferred to go to medical store /pharmacy for seeking treatment for tuberculosis. Similar finding was observed if the ASHA themselves find suspected tuberculosis patient in a community. Forty-one (95.34\%) ASHAs would like to send suspected tuberculosis patient to hospital, however maximum of them i.e. $38(88.37 \%)$ have chosen to send them to Government Hospital. Two $(4.65 \%)$ did not give any response but no one wanted to give an advice to take medicines at home and rest.

More than half of ASHAs i.e. 25 (58.14\%) were found to be working as DOT provider. Forty $(93.02 \%)$ ASHAs knew DOT providers in their area. Thirty two $(80 \%)$ of them were helping DOT providers and $5(12.5 \%)$ were not, however 3 (7.5\%) ASHAs did not give any response. We could not find similar studies on ASHAs. This study 
may be the first of its kind which attempted to assess KAP of ASHAs pertaining to tuberculosis and its management practices.

\section{Conclusion and recommendations}

Good knowledge, favourable attitudes and practices pertaining to tuberculosis was observed amongst ASHAs but revealed gaps in the knowledge about BCG vaccination and major symptoms of pulmonary tuberculosis. All ASHAs in present study were well versed with recent guidelines of RNTCP about diagnosis of pulmonary TB suspects. For better understanding regarding tuberculosis and other health related issues, methodologies like quiz competition, group discussion, posters, role play, printed handouts, film show, setting up novel examples etc. need to be incorporated in training programme of ASHAs. Relaxation regarding age and education selection criteria of ASHA may be helpful to accommodate those women who do not fulfil the criteria but having strong social motivation and efficient learning capacity.

Key points:

- All ASHAs were well versed with recent guidelines of RNTCP about diagnosis of pulmonary TB suspects i.e. cough with or without expectoration for 2 or more than 2 weeks rather than 3 weeks.

- Two third of ASHAs (67.44\%) knew that the tuberculosis diagnosis and DOTS is totally free of cost.

- $90.69 \%$ of ASHAs felt compassion and desired to help tuberculosis patients.

\section{References}

1. Abhay Shukla (2005) National Rural Health MissionHope or disappointment? Indian J. Public Health. 49(3), 128.

2. Advocacy, communication and social mobilization (ACSM) (2011) for TB control: a guide to developing knowledge, attitude and practice surveys. Retrieved March 18, from http://www.stoptb.org/assets/ documents/ resources/publications/acsm/ ACSM_KAP\%20GUIDE.pdf

3. Baseline KAP Study Under RNTCP (2011) Project Submitted to Central TB Division, Ministry of Health \& Family Welfare, Government of India. Submitted By R K SWAMY BBDO Advertising Pvt. Ltd. in Association with Centre for Media Studies. Retrieved April 6, 2011 from http://www.tbcindia.org/pdfs/ Baseline\%20KAP\%20Study \%20under\%20RNTCP \%20Project\%20-\%20CMS.pdf.

4. Guidelines on Accredited Social Health Activists (ASHA) (2011) Annex.1 Retrieved March 18, from http://mohfw.nic.in/NRHM/RCH/guidelines/ASHA_gui delines.pdf

5. Hashim DS, Al Kubaisy W and Al Dulayme A (2003) Knowledge, attitude and practices survey among health care workers and tuberculosis patients in Iraq. Eastern Mediterranean Health J. 9(4), 718-730.
Vol. 5 No. 3 (Mar 2012)

ISSN: 0974- 6846

6. Hota PK and Dobe M (2005) Guest Editorial-National Rural Health Mission. Indian J. Public Health. 49(3), 108.

7. Majra JP (2008) Frequently asked questions by the patients on DOTS therapy and the answer given by the DOTS providers. NTI Bull. 44(3\&4), 1-3.

8. Mengiste M Mesfin, Tesfay W Tasew, Israel G Tareke and Madeley RJ Richard (2005) Community health workers: Their knowledge on pulmonary tuberculosis and willingness to be treatment supervisors in Tigrey, Northern Ethiopia. Ethiop. J. Health Dev. (Special Issue), 28-34.

9. Muhammad Umair Mushtaq et al. (2011) UrbanRural inequities in knowledge, attitude and practices regarding tuberculosis in two districts of Pakistan's Punjab Province. Int.J.Equity Health. 10, 1-8.

10. Neeta Singla, Sharma PP and Jain RC (1998) Awareness about tuberculosis among nurses working in a tuberculosis hospital and in a general hospital in Delhi, India. Int. J. Tuberc Lung Dis. 2(12), 10051010.

11. Park K (2009) Textbook of preventive and social medicine. 20th ed. Banarsidas Bhanot Publ., Jabalpur. pp: 160.

12. Reading material for ASHA (2006) Book No-4 Retrieved March 18, 2011 from http://mohfw.nic.in/NRHM/asha.htm

13. Srivastava DK, Prakash S, Adhish V, Nair KS, Gupta $S$ and Deoki Nandan (2009) A study of interface of ASHA with the community and service providers in Eastern Uttar Pradesh. Indian J. Public Health. 53(3), 133-136.

14. Suryakanta AH (2010) Community medicine with recent advances. 2nd ed. Jaypee Brothers Medical Publ. (P) Ltd. India. pp: 340.

15. Thamer Kadum et al. (2009) Survey of knowledge, attitudes and practices: Enhanced response to TB ACSM, Iraq. Middle East J. Family Med. 7(1), 23-38. 